\title{
La situación escolar de niñas y niños rurales en México
}

\section{Patricia E. Muñiz M.*}

A pesar de los avances en la cobertura del sistema educativo, subsisten los problemas de una alta proporción de niños rurales que no asisten a la escuela, que adolecen de rezago o atraso en su trayectoria escolar, o que abandonan la escuela sin haber terminado el ciclo elemental de la educación básica. Este trabajo tiene como propósito examinar la situación escolar de los niños entre 6 y 16 años de las localidades altamente marginadas del país e identificar algunas caracteristicas propias de sus hogares que influyan sobre ella. El análisis permitió reconocer un problema de edad al ingreso a la escuela que define una situación de atraso para un buen número de niños y sobre todo de niñas en condición de pobreza extrema. Los datos sobre asistencia escolar también mostraron un fenómeno masivo de abandono a edades tempranas que afectan a esos mismos grupos. Se destacaron algunas de las caracteristicas de los menores y de sus hogares como factores asociados a la asistencia escolar.

\section{Introducción}

Las últimas décadas en México se han caracterizado por continuados esfuerzos del Estado para ampliar la cobertura del sistema educativo. Cuando menos desde 1990 las estadísticas oficiales muestran que la proporción de niños en edad escolar ( 6 a 16 años) que nunca asistieron a la escuela ha descendido sistemáticamente, estimándose en $2.5 \%$ para 1995. Según la opinión de los expertos, estos niveles resultan prácticamente imposibles de superar, ya que reflejan fundamentalmente la situación de una parte de la población rural que reside en localidades muy pequeñas y mal comunicadas, en las que no existen escuelas y donde difícilmente podrían establecerse.

A pesar de estos avances en la cobertura del sistema educativo, subsisten los problemas de una alta proporción de niños que no asisten a la escuela, que adolecen de rezago o atraso en su trayectoria escolar, o abandonaron la escuela sin haber terminado el ciclo elemental de la educación básica (Muñoz y Suárez, 1996). A este respecto, se ha señalado la fuerte caída en la asistencia escolar de un ciclo a otro, y el continuo adelgazamiento de la población escolar a medida que se asciende por la escalera educativa (Guevara Niebla, 1992).

En particular, ha llamado la atención la fuerte proporción de niños que dejan la escuela después de cuatro o cinco años de asistir a

\footnotetext{
* Programa de Educación Salud y Alimentación (Progresa).
} 
ella y el pausado aumento de los años de escolaridad promedio de la población. Asimismo, se ha señalado la diferencia creciente por sexo, sobre todo a partir del paso de la educación primaria a la secundaria, que significa menores oportunidades de futuro para las niñas.

La crisis económica de los ochenta, el deterioro de los niveles de vida de la población, el avance de la investigación social y la creciente percepción del papel de los determinantes de género, sobre todo entre los sectores más pobres, llevaron al desarrollo de programas especiales destinados a combatir la pobreza en varios frentes. Bajo el supuesto de que el acceso a una educación básica es una condición indispensable para mejorar las oportunidades de bienestar futuro de los niños más pobres, los programas buscan contribuir a aumentar la escolaridad de los niños y, en especial, de las niñas, que han sido señaladas como víctimas de sesgos de género en la oferta de las oportunidades educativas. Ello ha permitido obtener información detallada sobre los problemas del acceso a la escuela, el rezago educativo y la deserción de los niños de aquellas localidades que fueron quedando como representantes de las situaciones que se han visto como límites de la expansión de la cobertura del sistema educativo y que podría suponerse son las que han sido menos beneficiadas por los procesos de desarrollo.

Este trabajo se inscribe dentro de estas preocupaciones, y se propone examinar la situación escolar de los niños entre 6 y 16 años de las localidades altamente marginadas del país. Después de una descripción de las fuentes de información, se analiza la asistencia a la escuela, el abandono de los estudios, y el rezago, comparando los datos nacionales con los de los niños de las localidades marginadas. Los resultados permiten sugerir la importancia de la edad al ingreso y a la salida de la escuela. Esto lleva a presentar en la siguiente sección un análisis de los factores que se asocian con la falta de asistencia a la escuela, distinguiendo entre los niños de 6 a 10 años y los de 11 a 16 años. Entre las variables que se exploran se destacan las referentes a las características de los niños y de sus hogares.

\section{Las fuentes de información y el universo de estudio}

La información utilizada en este trabajo proviene de dos fuentes: el Conteo nacional de población y vivienda, 1995 (Conteo-95) del Instituto Nacional de Estadística, Geografia e Informática (INEGI) y la Encuesta 
de las Características Socieoeconómicas de los Hogares (Encaseh) del Programa de Educación, Salud y Alimentación. ${ }^{1}$

El Conteo-95 combinó una enumeración exhaustiva de toda la población y las viviendas del país con una encuesta que profundizó las características captadas por la enumeración; además se incluyeron algunos otros temas de interés sociodemográfico. La encuesta se levantó del 6 de noviembre al 2 de diciembre de 1995. Las unidades de análisis para la enumeración fueron las viviendas particulares habitadas y sus residentes habituales. La encuesta incluyó además a los hogares (para cada hogar en el interior de la vivienda se levantó un cuestionario) y a los migrantes internacionales. El cuestionario de la enumeración captó información sobre los servicios en la vivienda y algunas características de los residentes habituales, como sexo, edad, alfabetismo y lengua. En la encuesta se incluyeron los mismos temas, tratándolos con mayor detalle, y se consideraron temas adicionales.

La Encaseh es el instrumento que utiliza Progresa para recoger el censo de las localidades rurales de muy alta y alta marginalidad seleccionadas para la operación del programa. La selección de las localidades según su grado de marginación se basa en elementos homogéneos en la nación, siguiendo un procedimiento estandarizado que se obtiene mediante la construcción de un índice básico de marginación para cada una de las localidades en el territorio nacional para las que se cuenta con información censal sociodemográfica. ${ }^{2}$

Una primera aproximación tentativa a los hogares que viven en condición de pobreza extrema se hace a partir del ingreso familiar y

\footnotetext{
${ }^{1}$ A mediados de 1997 se puso en marcha un nuevo programa para combatir la pobreza extrema en México cuyo propósito es que las familias en condiciones de pobreza extrema tengan a su alcance oportunidades genuinas de satisfacer las necesidades básicas que representan la educación, la salud y la alimentación. Los objetivos principales de Progresa son: $a$ ) Proporcionar apoyo a las familias que viven en condiciones de pobreza extrema, para ampliar sus oportunidades y capacidades de lograr mayores niveles de bienestar; b) mejorar las condiciones de educación, salud y alimentación de las familias pobres, particularmente de los niños, las niñas y sus madres, brindando suficientes servicios escolares y de cuidado de la salud de calidad, así como ayuda alimentaria y, c) integrar estas acciones para que el aprovechamiento escolar no se vea afectado por la falta de salud o la desnutrición de los niños y jóvenes, ni porque éstos realicen labores que dificulten su asistencia escolar. Para fines de 1999 el Programa beneficiaba a cerca de 2.6 millones de familias.

${ }^{2}$ Este indice se construye mediante indicadores de marginación, sobre los que se aplica la técnica de componentes principales para obtener una variable resumen que concentra la mayor variación de la información entre las localidades. Los valores del indice se interpretan mediante un análisis comparativo entre las localidades. Los indi-
} 
de la línea de pobreza extrema, ${ }^{3}$ clasificando a los hogares en dos grupos. A partir de esta identificación preliminar se lleva a cabo una segunda clasificación de los hogares que considera un conjunto de indicadores sociales y económicos derivados de la información obtenida por medio del censo. El propósito es lograr una aproximación multidimensional a la condición de pobreza del hogar; para ello se utiliza el procedimiento de análisis discriminante, mediante el cual es posible la clasificación de un hogar en alguno de los dos grupos de interés: en condición de pobreza extrema y no en pobreza extrema, en términos de las características particulares del hogar.

Cabe aclarar que de esta forma los hogares que están en condición de pobreza extrema y los que no se encuentran en esa situación se ubican en las mismas localidades rurales, lo que permite una comparación de hogares en diferentes situaciones dentro de un contexto similar. Por otro lado, dado que el censo en las localidades visitadas por Progresa es la base para la selección de los hogares a ser apoyados por el Programa, la información de que se dispone es previa a la aplicación de éste.

Es importante notar que dadas las características de los apoyos que entrega Progresa a las familias, es necesario asegurar la oferta de servicios de educación básica, si no en la misma localidad, a una distancia no mayor a $5 \mathrm{~km}$. Por tanto, en este análisis como en los subsecuentes, el problema de la inexistencia de una oferta de servicios educativos, que podría tener efecto sobre la asistencia escolar de la población infantil y joven, sobre el abandono y los bajos niveles de escolaridad se anula en la misma selección de localidades, en lo que se refiere a la información de Progresa, no así en la relativa al contexto nacional. Si bien es cierto que en las localidades del Programa podrían existir problemas como las diferencias en las distancia y los costos de transporte.

La primera sección del cuestionario pregunta sobre las características sociodemográficas de todos los miembros de los hogares: sexo,

cadores utilizados para construir el índice de marginación de las localidades son los siguientes: porcentaje de población analfabeta de 15 años o más, porcentaje de viviendas sin agua, porcentaje de viviendas sin drenaje, porcentaje de viviendas sin electricidad, número promedio de ocupantes por cuarto, porcentaje de viviendas con piso de tierra, y porcentaje de población ocupada en el sector primario.

${ }^{3}$ La línea se obtiene mediante la evaluación del ingreso mensual per cápita de los hogares en comparación con el costo de una canasta básica alimentaria que satisface los requerimientos mínimos para evitar la desnutrición, enfermedades y deficiencias antropométricas. 
edad, analfabetismo, escolaridad, asistencia escolar, condición de actividad, e ingresos. La segunda recopila información sobre las características de los hogares, características de las viviendas, posesión de enseres, tierras y animales domésticos, así como las relaciones de parentesco, tamaño y migración de los miembros de los hogares.

Los datos de la Encaseh corresponden a una muestra aleatoria de 100000 hogares de los aproximadamente 1.95 millones censados por Progresa entre diciembre de 1996 y mayo de 1998 en cerca de 37000 localidades rurales de alta y muy alta marginalidad de 30 estados de la República Mexicana. Estas localidades representan $35.4 \%$ de las localidades de menos de 5000 habitantes y $47.5 \%$ del total de las de mayor marginación, representando $76.5 \%$ del total los 15.3 millones de personas que residen en las localidades de alta y muy alta marginación en el país.

La información que analizamos en este trabajo, tanto la correspondiente al Conteo como la Encaseh, se refiere a preguntas similares y fue trabajada de la misma forma; la que corresponde al Conteo95 presenta los datos expandidos de la muestra nacional y la de Progresa es el número total de niñas y niños de las localidades rurales de esta muestra.

\section{La situación escolar de las niñas y niños}

\section{Asistencia escolar}

Examinaremos aquí la situación de la asistencia escolar de los niños, el ingreso diferencial al sistema escolar, el rezago, y la distribución por edad en los diferentes niveles de la educación básica. En los apartados correspondientes presentamos primero la información del contexto nacional y después la que se refiere a los niños de las localidades marginadas, distinguiendo estos últimos por la condición de pobreza extrema de sus hogares.

Una manera de iniciar el estudio de la eficiencia (cobertura) del sistema escolar es señalando el porcentaje de niños en edad escolar -entre 6 y 16 años- que nunca han asistido a la escuela. Según el Conteo-95, $2.5 \%$ del total de niños en edad escolar no había asistido nunca a la escuela (cuadro 1). Al revisar la información por edad simple, advertimos que el porcentaje de niños que nunca han asistido alcanza su punto más alto a los seis años, para empezar a disminuir desde los $7 \mathrm{y}$ 
CUADRO 1

Proporción de niños y jóvenes que nunca asistieron a la escuela por edad y sexo según localidad de residencia, 1995

\begin{tabular}{rrrrrrrrr}
\hline Edad & Nacional & Urbano & \multicolumn{1}{c}{ Rural } & Hombres & \multicolumn{2}{c}{ Mujeres } & $\begin{array}{c}\text { Hombres } \\
\text { rurales }\end{array}$ & $\begin{array}{c}\text { Mujeres } \\
\text { rurales }\end{array}$ \\
\hline 6 & 6.35 & 4.08 & 11.35 & 6.27 & 6.45 & 11.78 & 10.91 \\
7 & 2.78 & 1.60 & 5.65 & 2.70 & 2.87 & 5.98 & 5.30 \\
8 & 1.75 & 0.98 & 3.37 & 1.76 & 1.73 & 3.22 & 3.52 \\
9 & 1.41 & 0.77 & 2.81 & 1.42 & 1.41 & 2.42 & 3.20 \\
10 & 1.61 & 1.15 & 2.63 & 1.69 & 1.53 & 2.76 & 2.50 \\
11 & 1.19 & 0.88 & 1.87 & 1.18 & 1.20 & 1.53 & 2.23 \\
12 & 1.48 & 0.85 & 2.85 & 1.27 & 1.70 & 2.38 & 3.37 \\
13 & 1.66 & 0.99 & 3.21 & 1.55 & 1.77 & 2.86 & 3.54 \\
14 & 1.49 & 0.91 & 2.82 & 1.43 & 1.55 & 2.87 & 2.76 \\
15 & 2.04 & 1.07 & 4.28 & 2.23 & 1.86 & 4.48 & 4.07 \\
16 & 2.33 & 1.61 & 4.11 & 2.12 & 2.54 & 3.89 & 4.36 \\
\hline
\end{tabular}

hasta los 11, edad a la que alcanza el valor mínimo y vuelve a aumentar hasta llegar a $2.33 \%$ a los 16 años.

Tomando en cuenta el tipo de localidad de residencia de los niños, se observa para el conjunto de 6 a 16 años, que los porcentajes de aquellos que nunca han asistido son $1.4 \%$ para las zonas urbanas y $4.22 \%$ para las rurales. ${ }^{4}$ Las proporciones más altas se encuentran entre los niños de seis y siete años: 11.35 y $5.65 \%$ en áreas rurales y 4.08 y $1.60 \%$ en urbanas. La disminución de los porcentajes sigue la misma tendencia descrita para el total nacional, hasta los 11 años, pero el aumento de la proporción de los que nunca han ido a la escuela es mucho mayor entre los niños rurales, llegando a triplicar o cuadruplicar la de los niños urbanos en los tramos finales. No se observan diferencias por sexo en el agregado (para el nivel nacional, 2.23 y $2.27 \%$, respectivamente) ni al distinguir por edades simples ni si sólo se atiende a las localidades rurales (alrededor de 4 por ciento).

Para el total de niños en edad escolar de las localidades marginadas, el porcentaje de los que nunca asistieron es $7.2 \%$, mayor a lo reportado por el Conteo años antes para las localidades rurales. Una

${ }^{4}$ La definición del tipo de localidad de residencia sigue un criterio de tamaño de población; así, las localidades rurales están definidas como aquellas que tienen menos de 2500 habitantes, y las urbanas tienen 2501 y más habitantes. 
CUADRO 2

Proporción de niños y jóvenes que nunca asistieron a la escuela por edad y sexo en localidades rurales marginadas

\begin{tabular}{ccccc}
\hline & \multicolumn{2}{c}{ No pobres } & \multicolumn{2}{c}{ Pobres } \\
\cline { 2 - 3 } Edad & Hombres & Mujeres & Hombres & Mujeres \\
\hline 6 & 9.04 & 10.78 & 21.18 & 21.23 \\
7 & 4.10 & 4.97 & 9.91 & 10.21 \\
8 & 1.68 & 1.79 & 6.01 & 6.14 \\
9 & 2.34 & 1.02 & 4.66 & 4.73 \\
10 & 1.01 & 2.16 & 4.65 & 4.85 \\
11 & 1.73 & 1.58 & 4.28 & 4.23 \\
12 & 2.24 & 1.41 & 4.40 & 5.53 \\
13 & 1.42 & 1.94 & 4.53 & 5.05 \\
14 & 2.49 & 3.11 & 5.47 & 6.18 \\
15 & 1.88 & 2.08 & 5.75 & 7.31 \\
16 & 2.92 & 3.91 & 6.89 & 7.94 \\
Total & 2.64 & 2.94 & 7.22 & 7.75 \\
\hline
\end{tabular}

mirada global al cuadro 2 permite observar que la proporción de niños pobres extremos que nunca asistieron a la escuela es más del doble que la de los no pobres $^{5}$ en todas las edades y para ambos sexos.

$\mathrm{Al}$ revisar la información por edad simple, se observa que los porcentajes de niños que nunca asistieron a la escuela son muy altos para los niños de las primeras edades, sobre todo para los de seis años, y más entre los pobres: una quinta parte de niños y niñas nunca ha asistido a la escuela (21.18\% para los niños y $21.23 \%$ para las niñas). Entre los niños no pobres la proporción de los que nunca han asistido a la escuela es relativamente pequeña a partir de los 8 años, y presenta diferencias no sistemáticas por sexo (en algunas edades la proporción de niños es mayor y en otras, la de las niñas). En cuanto a los ninos en condiciones de pobreza, la proporción que no asiste a la escuela es todavía alta a los ocho años y se conserva prácticamente para todas las edades. Para los pobres extremos se presentan diferencias sistemáticas por sexo: en casi todas las edades la proporción de niñas que nunca han asistido es superior a la de los niños.

${ }^{5}$ La categoría de no pobre es la que se refiere a los hogares y los menores cuya condición no fue definida como pobreza extrema, es decir, se refiere a aquellos que no son pobres extremos. Sin lugar a duda, la mayor parte de estos hogares también son pobres, pero no extremos. 
Aunque estos datos constituyen una aproximación muy general al estudio de la cobertura del sistema escolar, y requieren ser complementados con otra información, apuntan a otro problema de interés, a saber: el grado en que se cumple el supuesto normativo que define la trayectoria regular con respecto a la edad en que los niños ingresan a la escuela.

El Estado se obliga a proporcionar educación básica (es decir, primaria y secundaria) a todos los niños en edad escolar. Desde el punto de vista del ingreso, concretamente en México esto significa que las escuelas sólo aceptan niños que tienen cuando menos seis años cumplidos; y desde el punto de vista del tiempo exigido por la escolarización, que en principio durante nueve años el niño será estudiante. Con ello se establece una norma o un criterio que supone regularidad en la trayectoria escolar de los niños y que permite evaluar aspectos de la cobertura del sistema escolar, de su desempeño y del de los niños.

Si el supuesto se cumple y no hay otros factores que atenten contra él, un niño inscrito en una escuela al cumplir seis años, adelantaría cada año un grado. En este caso, la trayectoria educativa de primaria tendría una duración de seis años, y la de secundaria, otros tres. Un niño inscrito en la escuela al cumplir seis años y que cursara regularmente sus estudios, tendría 12 años al terminar la primaria y 15, al terminar la secundaria. Sin embargo, y puesto que no siempre coinciden la fecha de inicio del periodo escolar con el momento en que un niño cumple los seis años, cabe esperar cierta fluctuación en la edad en que ingresa a la escuela y, en consecuencia, en la que debería terminar cada ciclo. Si la carencia de trayectoria define la falta de acceso a la escuela, la trayectoria regular o normal permite definir otros dos tipos de situaciones: el atraso o rezago y la deserción. La primera consiste en que el niño que ha ingresado al sistema escolar no mantiene la relación esperada entre la edad alcanzada y el grado terminado, y la segunda, en que el niño en algún momento abandona definitivamente los estudios.

Los datos presentados en esta sección permiten cuestionar la adecuación de los supuestos acerca de la trayectoria escolar. En las localidades rurales marginadas la proporción de niños pobres extremos de seis a ocho años que nunca han asistido a la escuela es superior a $35 \%$, lo que podría significar que a una parte importante de los niños está en situación de "atraso" escolar ex-ante. Por otro lado, cabría preguntarse por la clase de factores que explican las tasas de inasistencia. En 
relación con lo primero, la literatura sobre el tema ha indicado que el retraso en que incurre un niño en su trayectoria puede ser un elemento de primera importancia para explicar la deserción. ${ }^{6}$

\section{Abandono escolar}

Otro aspecto que llama la atención al examinar la situación de los niños que asisten a la escuela es la tendencia a dejar de hacerlo en edades tempranas. Salvo en el grupo de seis años, entre los 7 y los 11 años la proporción de niños que asisten a la escuela es superior a $96 \%$, de esta última edad en adelante el porcentaje de los que asisten a la escuela empieza a decrecer en forma muy marcada hasta reducir la asistencia escolar sólo a la mitad de las personas de 16 años. Al distinguir por tipo de localidad de residencia, dentro de una tendencia similar a la descrita, se evidencia con toda claridad la desventaja de los niños rurales con respecto a los de las zonas urbanas, siendo mucho más notorias estas diferencias entre mayor es la edad. Así, mientras entre los niños rurales de 15 años la proporción de los que siguen asistiendo a la escuela es de $40.7 \%$, para los urbanos es de $69.3 \%$; para aquellos que tienen 16 años, los que asisten a la escuela representan 28.5 y $60.6 \%$, entre los rurales y los urbanos respectivamente (véase el cuadro 3).

$\mathrm{Al}$ distinguir por sexo los datos muestran tendencias similares a las descritas: a partir de los 11 de años edad los porcentajes de asistencia escolar para las mujeres son menores que para los hombres. Esta situación se vuelve todavía más drástica cuando se refiere a las mujeres de las zonas rurales; sólo cerca de una tercera parte de las niñas de 15 años y menos de una cuarta parte de las de 16 años asiste a la escuela. Esta última proporción representa menos de la mitad en relación con las mujeres a nivel nacional.

En las áreas rurales con mayor marginación se observa un porcentaje similar de asistencia de niños de seis años, es decir, con el mismo re-

\footnotetext{
${ }^{6}$ Entre los escasos estudios existentes en México, cabe mencionar los trabajos de Muñoz Izquierdo (1994) y Muñoz Izquierdo y Lavín de Arrivé (1988). Muñoz Izquierdo compara alumnos de primero y quinto grados y advierte que quienes han llegado a este último iniciaron sus estudios a una edad más próxima a los seis años y tienen menores tasas de repetición. Sin embargo, los datos relativos a los niños de quinto año se refieren sólo a aquellos que lograron llegar a ese grado y no al total de los que podrían haberlo hecho. Los datos de la Encaseh, por el contrario, se refieren a la situación escolar del total de niños en cada edad.
} 


\section{CUADRO 3}

Proporción de niños que asisten a la escuela por edad y sexo, según localidad de residencia, 1995

\begin{tabular}{|c|c|c|c|c|c|c|c|}
\hline Edad & Total & Rural & Urbano & Hombres & Mujeres & $\begin{array}{c}\text { Hombres } \\
\text { murales }\end{array}$ & $\begin{array}{c}\text { Mujeres } \\
\text { murales }\end{array}$ \\
\hline 6 & 92.36 & 87.10 & 94.75 & 92.31 & 92.41 & 86.73 & 87.48 \\
\hline 7 & 96.67 & 93.76 & 97.87 & 96.88 & 96.45 & 93.62 & 93.91 \\
\hline 8 & 97.24 & 95.04 & 98.27 & 96.94 & 97.53 & 94.81 & 95.28 \\
\hline 9 & 97.65 & 95.76 & 98.51 & 97.62 & 97.67 & 95.83 & 95.69 \\
\hline 10 & 97.00 & 94.90 & 97.95 & 96.88 & 97.12 & 94.80 & 94.99 \\
\hline 11 & 96.12 & 93.84 & 97.14 & 96.32 & 95.91 & 93.98 & 93.68 \\
\hline 12 & 91.11 & 84.14 & 94.28 & 92.93 & 89.11 & 87.05 & 80.88 \\
\hline 13 & 84.20 & 72.32 & 89.40 & 86.57 & 81.98 & 76.35 & 68.48 \\
\hline 14 & 76.96 & 60.15 & 84.24 & 79.07 & 74.83 & 64.03 & 56.14 \\
\hline 15 & 60.59 & 40.66 & 69.29 & 63.03 & 58.23 & 47.36 & 34.08 \\
\hline 16 & 51.38 & 28.52 & 60.58 & 53.51 & 49.42 & 32.42 & 24.28 \\
\hline
\end{tabular}

traso ya señalado (cuadro 4). Para los no pobres, la proporción de niños entre 7 y 10 años que asisten a la escuela es igual o superior a $95 \%$; en las siguientes edades el porcentaje de los que asisten a la escuela empieza a decrecer en forma muy marcada hasta reducir la asistencia escolar sólo a la tercera parte de las personas de 16 años, con un decremento mayor para las mujeres que para los hombres a partir de los 12 años.

\section{CUADRO 4}

Proporción de niños que asisten a la escuela por edad y sexo, en localidades rurales marginadas, según condición de pobreza

\begin{tabular}{ccccc}
\hline & \multicolumn{2}{c}{ No pobres } & \multicolumn{2}{c}{ Pobres } \\
\cline { 2 - 3 } Edad & Hombres & Mujeres & Hombres & Mujeres \\
\hline 6 & 90.11 & 87.97 & 76.77 & 77.04 \\
7 & 94.71 & 93.37 & 88.23 & 87.50 \\
8 & 97.59 & 97.07 & 91.47 & 91.35 \\
9 & 95.83 & 96.93 & 92.41 & 92.13 \\
10 & 96.85 & 96.04 & 91.50 & 91.30 \\
11 & 94.20 & 95.50 & 90.05 & 90.02 \\
12 & 91.47 & 88.35 & 84.88 & 79.65 \\
13 & 87.03 & 78.32 & 74.62 & 65.52 \\
14 & 77.62 & 67.88 & 59.73 & 51.66 \\
15 & 63.94 & 53.39 & 44.75 & 36.14 \\
16 & 37.13 & 33.98 & 33.76 & 25.12 \\
Total & 81.17 & 77.24 & 76.96 & 73.67 \\
\hline
\end{tabular}


Entre los pobres, si bien la tendencia es similar, los porcentajes de asistencia escolar son mucho menores en las primeras edades: entre la población de seis años son prácticamente tres cuartas partes de ambos sexos los que asisten a la escuela y la proporción de los que asisten a los siete años es muy similar a la que presentan los niños de seis años de las familias no pobres. Entre los 8 y 11 años asiste alrededor de $91 \%$. Si bien es cierto que en todas las edades la asistencia de los niños pobres extremos es alrededor de cinco puntos porcentuales menor que la de los no pobres de las mismas localidades, a partir de los 11 años, además del decremento paulatino de la asistencia escolar, la diferencia entre pobres y no pobres se incrementa. Mientras entre los niños de 15 años $64 \%$ de los varones y $54 \%$ de las mujeres no pobres asisten a la escuela, entre los pobres estas proporciones ascienden a 44.7 y $36.1 \%$, respectivamente. Es decir, existe una diferencia de 19 puntos porcentuales entre los hombres y 17 puntos entre las mujeres con respecto a este indicador según la condición de pobreza de sus hogares.

Así, dentro de las zonas rurales marginadas son precisamente los niños de los hogares en condiciones de pobreza extrema quienes muestran las más bajas proporciones de asistencia escolar, sobre todo las niñas, que empiezan a reducir su asistencia más tempranamente que los varones. El carácter sistemático de la falta de asistencia a partir de los $10 \mathrm{u} 11$ años permite sostener que estamos frente a una tendencia al abandono escolar.

Si se considera en conjunto la información hasta aquí revisada, surge la imagen de una trayectoria escolar muy diferente de la que supone el criterio normativo de la política educativa. Una proporción importante de niños, sobre todo en las localidades rurales marginadas, ingresa tardíamente y deja de asistir a edades tempranas. Para ellos, la trayectoria educativa de hecho se reduce a un corto número de años, con el agravante de que desde el principio parecen encontrarse en situación de atraso. Esto plantea el problema de la relación entre edad y grado escolar aprobado. Si se acepta el supuesto de la trayectoria escolar normativa, hay rezago siempre que la edad del niño sea mayor que la que debería tener si hubiera empezado a los seis años y hubiera aprobado todos los cursos. Conviene examinar entonces esta relación.

\section{Edad al ingreso a la educación básica}

Con el fin de revisar el retraso que presentan los niños de localidades marginadas rurales con respecto a la edad normativa que marca el sis- 
tema escolar, presentamos dos indicadores. El primero se refiere a la edad promedio que tienen niñas y niños y la edad mediana al haber aprobado el grado escolar. Dado que la información procede de encuestas aplicadas a los hogares y que el nivel de escolaridad que se presenta corresponde a preguntas del tipo "último grado aprobado en la escuela", los cuadros hacen referencia a la edad que la persona tenía en el momento en que se aplicó la encuesta y el último grado que ya había aprobado. Así, se esperaría que los niños estuvieran cursando el grado siguiente a la edad promedio indicada. Como en los apartados anteriores, revisaremos primero el contexto nacional de 1995 distinguiendo entre niños y niñas que asisten a la escuela y los que no lo hacen.

La parte izquierda del cuadro 5 , que se refiere a los menores urbanos y rurales que asisten a la escuela, muestra que en general la edad promedio de los niños urbanos en cada uno de los grados escolares es ligeramente superior que la de las niñas urbanas. Por otra parte, los niños urbanos tienen una edad promedio menor, al haber aprobado cada grado escolar, que los niños rurales. Entre niñas y niños rurales se presenta una situación similar a la descrita para los urbanos de ambos sexos. Esta información parece no corroborar el retraso en el ingreso a la escuela de los niños rurales del país con respecto a la normatividad establecida.

\section{CUADRO 5}

Edad promedio en cada grado escolar por sexo y tipo de localidad de residencia según asistencia a la escuela, 1995

\begin{tabular}{|c|c|c|c|c|c|c|c|c|}
\hline & \multicolumn{8}{|c|}{ Localidades urbanas } \\
\hline & \multicolumn{4}{|c|}{ Asisten } & \multicolumn{4}{|c|}{ No asisten } \\
\hline & \multicolumn{2}{|c|}{ Hombres } & \multicolumn{2}{|c|}{ Mujeres } & \multicolumn{2}{|c|}{ Hombres } & \multicolumn{2}{|c|}{ Mujeres } \\
\hline & Media & Mediana & Media & Mediana & Media & Mediana & Media & Mediana \\
\hline $1^{\circ}$ prim. & 7.50 & 7 & 7.43 & 7 & 12.07 & 12 & 12.58 & 13 \\
\hline $2^{\circ}$ prim. & 8.61 & 8 & 8.49 & 8 & 13.37 & 14 & 13.19 & 13 \\
\hline $3^{\circ}$ prim. & 9.58 & 9 & 9.36 & 9 & 13.68 & 14 & 13.76 & 14 \\
\hline $4^{\circ}$ prim. & 10.61 & 10 & 10.39 & 10 & 14.38 & 14 & 14.03 & 14 \\
\hline $5^{\circ}$ prim. & 11.60 & 11 & 11.45 & 11 & 14.52 & 15 & 14.67 & 15 \\
\hline $6^{\circ}$ prim. & 12.56 & 12 & 12.40 & 12 & 14.77 & 15 & 14.51 & 15 \\
\hline $1^{\circ} \mathrm{sec}$ & 13.46 & 13 & 13.31 & 13 & 15.11 & 15 & 14.77 & 15 \\
\hline $2^{\circ} \mathrm{sec}$ & 14.43 & 14 & 14.22 & 14 & 15.31 & 15 & 15.25 & 16 \\
\hline $3^{\circ}$ sec. & 15.22 & 15 & 15.17 & 15 & 15.55 & 16 & 15.48 & 16 \\
\hline
\end{tabular}


CUADRO 5 (conclusión)

\begin{tabular}{|c|c|c|c|c|c|c|c|c|}
\hline & \multicolumn{8}{|c|}{ Localidades rurales } \\
\hline & \multicolumn{4}{|c|}{ Asisten } & \multicolumn{4}{|c|}{ No asisten } \\
\hline & \multicolumn{2}{|c|}{ Hombres } & \multicolumn{2}{|c|}{ Mujeres } & \multicolumn{2}{|c|}{ Hombres } & \multicolumn{2}{|c|}{ Mujeres } \\
\hline & Media & Mediana & Media & Mediana & Media & Mediana & Media & Mediana \\
\hline $1^{\circ}$ prim. & 8.13 & 8 & 7.95 & 8 & 12.76 & 13 & 12.62 & 13 \\
\hline $2^{\circ}$ prim. & 9.21 & 9 & 9.01 & 9 & 13.59 & 14 & 13.58 & 14 \\
\hline $3^{\circ}$ prim. & 10.26 & 10 & 9.99 & 10 & 14.19 & 15 & 14.00 & 14 \\
\hline $4^{\circ}$ prim. & 11.16 & 11 & 10.89 & 11 & 14.34 & 15 & 14.23 & 15 \\
\hline $5^{\circ}$ prim. & 12.02 & 12 & 11.90 & 12 & 14.62 & 15 & 14.46 & 15 \\
\hline $6^{\circ}$ prim. & 12.87 & 13 & 12.76 & 12 & 14.54 & 15 & 14.45 & 15 \\
\hline $1^{\circ} \mathrm{sec}$ & 13.77 & 14 & 13.49 & 13 & 14.91 & 15 & 14.68 & 15 \\
\hline $2^{\circ} \mathrm{sec}$ & 14.63 & 15 & 14.36 & 14 & 15.17 & 15 & 14.94 & 15 \\
\hline $3^{\circ} \mathrm{sec}$ & 15.20 & 15 & 15.16 & 15 & 15.56 & 16 & 15.46 & 16 \\
\hline
\end{tabular}

Con respecto a los menores que no asisten a la escuela (parte derecha del cuadro 5), la situación es completamente diferente y bien podría estar mostrando un gran rezago o una deserción del sistema escolar. No habría que olvidar que ellos representan un porcentaje menor que se incrementa con la edad de los niños. Sin embargo, lo que llama mucho la atención es la similitud entre hombres y mujeres independientemente del tipo de localidad de residencia.

La edad promedio de los niños y niñas de localidades rurales marginadas de nuestro país se presenta en el cuadro 6, que distingue también la asistencia escolar. Al revisar la información del primer recuadro (lado izquierdo), se puede constatar primeramente el retraso de los niños al ingresar a la primaria: hombres y mujeres, no pobres y pobres, cuentan con 6.6 años en promedio al aprobar preescolar y 7.8 años en el primer grado de primaria. Para el segundo grado de primaria la edad promedio de los niños y niñas es similar, sin embargo las medianas presentan diferencias a favor de las niñas: mientras la mitad de los niños en este grado escolar cuenta con nueve años, entre las niñas esta misma proporción cuenta con ocho años. Del tercer año de primaria al sexto, los niños avanzan un ciclo escolar por cada año de edad sin diferencias por sexo, en cuanto a las medianas y conservándose las edades promedio ligeramente más bajas para las niñas. A partir del primero de secundaria hay similitud en las edades promedio entre hombres y mujeres y vuelven a aparecer las ventajas para las niñas en las edades medias; sin embargo, no debe de olvidarse que a partir 


\section{CUADRO 6}

Edad promedio de los menores por grado escolar alcanzado según sexo, condición de pobreza y asistencia a la escuela en localidades rurales marginadas

\begin{tabular}{|c|c|c|c|c|c|c|c|c|}
\hline & \multicolumn{4}{|c|}{ No pobres que asisten } & \multicolumn{4}{|c|}{ No pobres que no asisten } \\
\hline & \multicolumn{2}{|c|}{ Hombres } & \multicolumn{2}{|c|}{ Mujeres } & \multicolumn{2}{|c|}{ Hombres } & \multicolumn{2}{|c|}{ Mujeres } \\
\hline & Media & Mediana & Media & Mediana & Media & Mediana & Media & Mediana \\
\hline $1^{\circ}$ prim. & 7.84 & 7 & 7.85 & 7 & 9.36 & 8.5 & 7.78 & 7 \\
\hline $2^{\circ}$ prim. & 8.86 & 9 & 8.81 & 8 & 12.79 & 14 & 11.75 & 12 \\
\hline $3^{\circ}$ prim. & 9.99 & 10 & 9.81 & 10 & 14.05 & 14 & 13.50 & 15 \\
\hline $4^{\circ}$ prim. & 11.04 & 11 & 10.83 & 11 & 14.12 & 15 & 14.20 & 15 \\
\hline $5^{\circ}$ prim. & 12.10 & 12 & 11.87 & 12 & 14.27 & 15 & 14.44 & 15 \\
\hline $6^{\circ}$ prim. & 12.99 & 13 & 12.78 & 13 & 14.44 & 15 & 14.16 & 14 \\
\hline $1^{\circ} \mathrm{sec}$ & 13.78 & 14 & 13.60 & 13 & 14.86 & 15 & 14.66 & 15 \\
\hline $2^{\circ}$ sec. & 14.53 & 15 & 14.43 & 14 & 15.07 & 15 & 14.70 & 15 \\
\hline \multirow[t]{4}{*}{$3^{\circ} \mathrm{sec}$} & 15.07 & 15 & 15.13 & 15 & 15.17 & 16 & 15.04 & 15 \\
\hline & \multicolumn{4}{|c|}{ Pobres que asisten } & \multicolumn{4}{|c|}{ Pobres que no asisten } \\
\hline & \multicolumn{2}{|c|}{ Hombres } & \multicolumn{2}{|c|}{ Mujeres } & \multicolumn{2}{|c|}{ Hombres } & \multicolumn{2}{|c|}{ Mujeres } \\
\hline & Media & Mediana & Media & Mediana & Media & Mediana & Media & Mediana \\
\hline $1^{\circ}$ prim. & 7.85 & 7 & 7.75 & 7 & 8.26 & 7 & 8.65 & 7 \\
\hline $2^{\circ}$ prim. & 9.06 & 9 & 8.86 & 9 & 11.57 & 12 & 11.08 & 11 \\
\hline $3^{\circ}$ prim. & 10.12 & 10 & 9.94 & 10 & 12.75 & 13 & 12.74 & 13 \\
\hline $4^{\circ}$ prim. & 11.12 & 11 & 10.92 & 11 & 13.45 & 14 & 13.45 & 14 \\
\hline $5^{\circ}$ prim. & 12.12 & 12 & 11.95 & 12 & 13.81 & 14 & 13.92 & 14 \\
\hline $6^{\circ}$ prim. & 13.06 & 13 & 12.89 & 13 & 14.12 & 15 & 14.13 & 14 \\
\hline $1^{\circ} \mathrm{sec}$ & 13.80 & 14 & 13.63 & 14 & 14.54 & 15 & 14.42 & 15 \\
\hline $2^{\circ} \mathrm{sec}$. & 14.62 & 15 & 14.44 & 14 & 14.62 & 15 & 14.53 & 15 \\
\hline $3^{\circ}$ sec. & 15.16 & 15 & 15.10 & 15 & 15.08 & 15 & 14.97 & 15 \\
\hline
\end{tabular}

de los 12 años la proporción de niñas que continúan asistiendo a la escuela disminuye drásticamente.

\section{Rezago escolar}

Para complementar el análisis anterior se presentan los años promedio de escolaridad alcanzada por los menores en cada una de las edades, distinguiendo entre los que asisten a la escuela y quienes no lo hacen (cuadros 7 y 8 ). En el cuadro 7 se eliminó los niños de seis 
CUADRO 7

Años promedio de estudio por edad, sexo y tipo de localidad de residencia, según asistencia a la escuela, 1995

\begin{tabular}{|c|c|c|c|c|c|c|c|c|}
\hline \multirow[b]{4}{*}{ Edad } & \multicolumn{8}{|c|}{ Localidades urbanas } \\
\hline & \multicolumn{4}{|c|}{ Asisten } & \multicolumn{4}{|c|}{ No asisten } \\
\hline & \multicolumn{2}{|c|}{ Hombres } & \multicolumn{2}{|c|}{ Mujeres } & \multicolumn{2}{|c|}{ Hombres } & \multicolumn{2}{|c|}{ Mujeres } \\
\hline & Media & Mediana & Media & Mediana & Media & Mediana & Media & Mediana \\
\hline 7 & 1.52 & 1 & 1.35 & 1 & 0.33 & 0 & 1.09 & 0 \\
\hline 8 & 1.86 & 2 & 1.95 & 2 & 0.83 & 0 & 0.51 & 0 \\
\hline 9 & 2.67 & 3 & 2.82 & 3 & 0.88 & 0 & 1.22 & 0 \\
\hline 10 & 3.52 & 4 & 3.67 & 4 & 0.95 & 0 & 0.74 & 0 \\
\hline 11 & 4.43 & 5 & 4.63 & 5 & 2.03 & 1 & 2.87 & 3 \\
\hline 12 & 5.37 & 6 & 5.48 & 6 & 3.41 & 3 & 3.85 & 4 \\
\hline 13 & 6.20 & 7 & 6.47 & 7 & 4.41 & 6 & 4.58 & 6 \\
\hline 14 & 7.15 & 8 & 7.38 & 8 & 5.12 & 6 & 5.31 & 6 \\
\hline 15 & 8.09 & 9 & 8.40 & 9 & 6.06 & 6 & 6.59 & 6 \\
\hline 16 & 8.87 & 9 & 9.09 & 9 & 6.57 & 6 & 6.58 & 6 \\
\hline
\end{tabular}

Localidades rurales

\begin{tabular}{|c|c|c|c|c|c|c|c|c|}
\hline \multirow[b]{3}{*}{ Edad } & \multicolumn{4}{|c|}{ Asisten } & \multicolumn{4}{|c|}{ No asisten } \\
\hline & \multicolumn{2}{|c|}{ Hombres } & \multicolumn{2}{|c|}{ Mujeres } & \multicolumn{2}{|c|}{ Hombres } & \multicolumn{2}{|c|}{ Mujeres } \\
\hline & Media & Mediana & Media & Mediana & Media & Mediana & Media & Mediana \\
\hline 7 & 1.46 & 1 & 1.36 & 1 & 0.60 & 0 & 0.17 & 0 \\
\hline 8 & 1.67 & 2 & 1.66 & 2 & 1.11 & 0 & 0.37 & 0 \\
\hline 9 & 2.39 & 2 & 2.42 & 3 & 0.90 & 0 & 0.38 & 0 \\
\hline 10 & 2.95 & 3 & 3.23 & 3 & 0.99 & 0 & 1.12 & 0 \\
\hline 11 & 3.93 & 4 & 3.94 & 4 & 2.42 & 2 & 2.07 & 2 \\
\hline 12 & 4.47 & 5 & 4.64 & 5 & 3.24 & 3 & 3.88 & 5 \\
\hline 13 & 5.30 & 6 & 5.64 & 6 & 4.07 & 6 & 4.25 & 6 \\
\hline 14 & 6.21 & 7 & 6.26 & 7 & 4.45 & 6 & 4.72 & 6 \\
\hline 15 & 7.04 & 8 & 7.18 & 8 & 5.13 & 6 & 5.46 & 6 \\
\hline 16 & 7.87 & 8 & 8.12 & 9 & 5.62 & 6 & 5.57 & 6 \\
\hline
\end{tabular}

años debido a que la información que arroja la encuesta resulta incongruente.

En relación con los años promedio de estudio en cada una de las edades entre aquellos menores que asisten a la escuela, se observa al 
distinguir por sexo que entre los niños y jóvenes urbanos, salvo a los siete años, las niñas acumulan mayor número de años promedio en cada una de las edades que los niños. En cuanto a aquellos de las zonas rurales sucede algo similar, salvo que el promedio de años es ligeramente menor en todas las edades. Al revisar la información correspondiente a aquellos que no asistían a la escuela en el momento en que fueron entrevistados se presenta una situación similar a la descrita para el caso de los que asisten, sin embargo en este caso tanto niñas como niños, urbanos y rurales, tienen alrededor de dos años en promedio menos de escolaridad.

Al centrar nuestra atención en las medianas que presenta el cuadro 7 , se observa que entre niños y niñas urbanos que asisten a la escuela no hay prácticamente diferencias. Los niños avanzan un año escolar por cada año de edad que acumulan, conforme a lo establecido "normativamente", llegando la mitad de hombres y mujeres de 15 y 16 años a cubrir nueve años de escolaridad. Con respecto a las diferencias por sexo entre la población de las áreas rurales, encontramos que a los nueve años de edad la mitad de los varones sólo ha acumulado dos años mientras que la mitad de las mujeres ya cuenta con tres años. Entre aquellos que cuentan con 16 años, para la mitad de los ninos el número de años aprobado es de ocho mientras que para las ninas es de nueve años de escolaridad.

Entre los menores que no asisten a la escuela volvemos a encontrar una situación similar a la descrita con respecto a la edad promedio de los niños en cada grado escolar. La mitad de los niños y niñas de 13 y más años cuenta tan sólo con seis años de escolaridad, independientemente del lugar en el que residen.

Bajo el supuesto de la "normatividad" de una trayectoria escolar regular, con cada año que los niños avancen de edad deberían acumular un grado o año escolar más, por lo que se esperaría que a la edad de ocho años los menores hubieran acumulado dos años y estuvieran cursando un tercero. Al revisar la información de los niños de las localidades marginadas, en el cuadro 8 se observa que entre aquellos que asisten a la escuela los niños no pobres que cuentan con 10 años tienen en promedio 3.3 años de escolaridad y la mitad de ellos sólo ha acumulado tres años. Esta situación es diferente para las niñas no pobres de la misma edad; la mitad de ellas cuenta ya con cuatro años de escolaridad. Tanto para los niños como para las niñas de 15 y 16 años el promedio de años de estudio acumulados ya presenta un rezago mayor: la mitad de ellos cuenta con sólo ocho años de escolaridad. 
CUADRO 8

Años promedio de escolaridad por edad simple en localidades marginadas rurales según condición de pobreza extrema y sexo

\begin{tabular}{|c|c|c|c|c|c|c|c|c|}
\hline \multirow[b]{3}{*}{ Edad } & \multicolumn{4}{|c|}{ No pobres que asisten } & \multicolumn{4}{|c|}{ No pobres que no asisten } \\
\hline & \multicolumn{2}{|c|}{ Hombres } & \multicolumn{2}{|c|}{ Mujeres } & \multicolumn{2}{|c|}{ Hombres } & \multicolumn{2}{|c|}{ Mujeres } \\
\hline & Media & Mediana & Media & Mediana & Media & Mediana & Media & Mediana \\
\hline 6 & 0.27 & 0 & 0.25 & 0 & 0.00 & 0 & 0.03 & 0 \\
\hline 7 & 0.90 & 1 & 0.90 & 1 & 0.20 & 0 & 0.20 & 0 \\
\hline 8 & 1.74 & 2 & 1.71 & 2 & 0.35 & 0 & 0.57 & 0 \\
\hline 9 & 2.60 & 3 & 2.64 & 3 & 0.91 & 0 & 1.68 & 2 \\
\hline 10 & 3.34 & 3 & 3.41 & 4 & 1.92 & 2 & 1.00 & 0 \\
\hline 11 & 4.04 & 4 & 4.20 & 4 & 2.18 & 2 & 2.09 & 2 \\
\hline 12 & 4.54 & 5 & 4.73 & 5 & 2.17 & 2 & 2.94 & 4 \\
\hline 13 & 5.74 & 5 & 5.94 & 7 & 3.08 & 3 & 3.67 & 4 \\
\hline 14 & 6.84 & 7 & 6.97 & 8 & 3.75 & 4 & 3.86 & 4 \\
\hline 15 & 7.47 & 8 & 7.56 & 8 & 5.73 & 5 & 5.83 & 7 \\
\hline \multirow[t]{3}{*}{16} & 7.66 & 8 & 7.76 & 8 & 6.44 & 9 & 6.08 & 8 \\
\hline & \multicolumn{4}{|c|}{ Pobres que asisten } & \multicolumn{4}{|c|}{ Pobres que no asisten } \\
\hline & \multicolumn{2}{|c|}{ Hombres } & \multicolumn{2}{|c|}{ Mujeres } & \multicolumn{2}{|c|}{ Hombres } & \multicolumn{2}{|c|}{ Mujeres } \\
\hline Edad & Media & Mediana & Media & Mediana & Media & Mediana & Media & Mediana \\
\hline 6 & 0.28 & 0 & 0.28 & 0 & 0.02 & 0 & 0.03 & 0 \\
\hline 7 & 0.89 & 1 & 0.95 & 1 & 0.13 & 0 & 0.18 & 0 \\
\hline 8 & 1.62 & 2 & 1.64 & 2 & 0.46 & 0 & 0.46 & 0 \\
\hline 9 & 2.37 & 2 & 2.42 & 2 & 0.83 & 0 & 0.83 & 0 \\
\hline 10 & 3.07 & 3 & 3.18 & 3 & 1.28 & 0 & 1.14 & 0 \\
\hline 11 & 3.76 & 4 & 3.87 & 4 & 1.66 & 1 & 1.59 & 1 \\
\hline 12 & 4.16 & 4 & 4.33 & 5 & 1.88 & 2 & 2.05 & 2 \\
\hline 13 & 5.02 & 5 & 5.27 & 5 & 2.43 & 2 & 2.59 & 3 \\
\hline 14 & 6.09 & 7 & 6.30 & 7 & 3.12 & 3 & 3.16 & 3 \\
\hline 15 & 6.91 & 8 & 7.06 & 8 & 4.19 & 4 & 4.00 & 4 \\
\hline 16 & 7.17 & 8 & 7.28 & 8 & 4.75 & 4 & 4.55 & 4 \\
\hline
\end{tabular}

Con respecto a los niños en condiciones de pobreza extrema, este fenómeno se observa desde edades más tempranas: tanto niños como niñas a los nueve años han acumulado sólo dos años de escolaridad y al llegar a los 12 años tienen un promedio de 4.16 y 4.33 años de escolaridad, respectivamente; la diferencia que se observa es que mientras la mitad de los varones de esa edad cuenta con cuatro años de educación, la mitad de las mujeres tiene cinco; sin embargo, ha- 
bría que recordar que la proporción de niñas que asisten a la escuela a esa edad es ligeramente inferior a la de los niños.

La información de los niños que no asisten a la escuela presenta una situación mucho más aguda y que bien podría sugerir que el nivel de escolaridad alcanzado al momento de la encuesta puede ser el definitivo, en particular para las personas de más edad. La mitad de los niños y niñas no pobres de ocho años no ha acumulado ningún año de escolaridad; $y$ entre los de 12 años los niños cuentan con apenas dos, mientras que las niñas lograron acumular cuatro años. Entre aquellos que viven en condiciones de pobreza extrema la situación es similar para los niños de 8 y 12 años, salvo que en este último caso la mitad de las niñas pobres sólo cuenta con dos años de escolaridad. Por último, entre los de 16 años el promedio de años de estudio se reduce a 4.5 .

Otra forma de aproximarse al rezago escolar es analizar la proporción de niños de cada una de las edades y el último año que han aprobado en la escuela. Tomando nuevamente criterios de normatividad como parámetro de comparación y considerando que la información con la que se cuenta en relación con la edad se refiere a años cumplidos y no a la edad exacta, se estableció un criterio "amplio", que toma en consideración que un niño a cierta edad cumplida podría haber aprobado cualquiera de tres grados cercanos a lo que se tendría de acuerdo a los criterios establecidos. Así, un niño de ocho años bien podría haber aprobado primero, segundo o tercer grado de primaria.

En términos generales, conforme avanza la edad el rezago suele ser mayor, tanto en la proporción de rezagados como en el número de años que se acumulan dentro de este rezago. Esta situación se presenta tanto para hombres como para mujeres, independientemente de su condición de pobreza. Sin embargo, la proporción de niños y niñas con rezago escolar en condiciones de pobreza extrema es superior a la de los no pobres.

$\mathrm{Al}$ analizar la situación de los niños no pobres se observa que entre aquellos que tienen 10 y 11 años de edad, la proporción de rezagados que asisten a la escuela es de 18.4 y $23.3 \%$, respectivamente. Dentro de estos últimos, la gran mayoría ( $14.4 \%$ para los de 10 y $13.7 \%$ para los de 11) corresponde a un año de atraso. A los 11 años, aquellos que cuentan con dos o tres y más años de rezago tienen porcentajes muy similares (6.8 y $7.7 \%$, respectivamente). En cuanto a las niñas no pobres la proporción de las que tienen algún 
rezago escolar es menor que la de los niños; las diferencias varían en cada una de las edades llegando a ser de 10 puntos porcentuales entre las de 12 años.

Con respecto a los menores de los hogares en condición de pobreza extrema, éstos muestran un rezago mayor que el de sus pares no pobres. Entre los 9 y los 12 años de edad, la proporción de niños pobres rezagados es superior en alrededor de 10 puntos porcentuales. En esta última edad mientras los niños pobres con dos y tres años de rezago tienen proporciones superiores a $10 \%(12.7$ y $10.1 \%$, respectivamente), entre los menores de hogares no pobres estos porcentajes ascienden a 7 y $4.5 \%$. Las niñas pobres presentan rezagos similares a los niños pobres, salvo que las proporciones en cada edad son inferiores en cinco o siete puntos porcentuales; la cantidad de años de rezago de niñas y niños también es similar.

CUADRO 9

Proporción de rezagados entre los niños que asisten a la escuela por edad, sexo y condición de pobreza en localidades marginadas

\begin{tabular}{|c|c|c|c|c|c|c|c|c|}
\hline & \multicolumn{4}{|c|}{ Hombres no pobres } & \multicolumn{4}{|c|}{ Mujeres no pobres } \\
\hline & Total & Un año & Dos años & Tres y más & Total & Un año & Dos años & Tres y más \\
\hline 8 & 5.67 & 5.67 & 0 & 0 & 4.86 & 4.86 & 0 & 0 \\
\hline 9 & 9.10 & 7.61 & 1.49 & 0 & 8.17 & 6.72 & 1.45 & 0 \\
\hline 10 & 18.35 & 14.40 & 3.02 & 0.93 & 15.63 & 11.13 & 4.13 & 0.38 \\
\hline 11 & 23.30 & 13.74 & 6.81 & 7.75 & 17.07 & 10.96 & 4.71 & 1.40 \\
\hline 12 & 30.43 & 18.84 & 7.07 & 4.53 & 20.85 & 11.81 & 5.32 & 3.72 \\
\hline 13 & 35.47 & 19.59 & 8.81 & 7.07 & 31.21 & 18.14 & 7.07 & 6.01 \\
\hline 14 & 36.46 & 16.57 & 11.05 & 8.84 & 30.93 & 14.42 & 8.39 & 8.13 \\
\hline 15 & 39.33 & 17.73 & 10.00 & 11.60 & 33.39 & 14.41 & 8.31 & 10.68 \\
\hline \multirow[t]{3}{*}{16} & 49.61 & 24.80 & 9.25 & 15.55 & 45.52 & 22.53 & 10.11 & 12.87 \\
\hline & \multicolumn{4}{|c|}{ Hombres pobres } & \multicolumn{4}{|c|}{ Mujeres pobres } \\
\hline & Total & Un año & Dos años & Tres y más & Total & Un año & Dos años & Tres y más \\
\hline 8 & 7.02 & 7.02 & 0 & 0 & 6.56 & 6.56 & 0 & 0 \\
\hline 9 & 18.16 & 15.91 & 2.24 & 0 & 16.31 & 14.23 & 2.08 & 0 \\
\hline 10 & 28.29 & 19.21 & 7.83 & 1.26 & 24.11 & 16.39 & 6.86 & 0.85 \\
\hline 11 & 33.26 & 19.36 & 9.25 & 4.66 & 29.56 & 18.04 & 7.60 & 3.92 \\
\hline 12 & 43.15 & 20.35 & 12.67 & 10.12 & 36.76 & 18.58 & 11.01 & 7.17 \\
\hline 13 & 52.83 & 24.72 & 14.46 & 13.65 & 47.12 & 25.01 & 11.32 & 10.79 \\
\hline 14 & 53.12 & 18.79 & 16.96 & 17.38 & 48.57 & 17.67 & 15.87 & 15.03 \\
\hline 15 & 54.15 & 18.15 & 15.38 & 20.63 & 49.15 & 16.53 & 14.46 & 18.17 \\
\hline 16 & 67.15 & 26.62 & 13.72 & 26.81 & 58.72 & 22.54 & 11.23 & 24.96 \\
\hline
\end{tabular}


Para complementar la información que hemos revisado hasta este momento presentamos un conjunto de gráficas que muestran la proporción de niños de las distintas edades en cada uno de los grados escolares; cada recuadro hace referencia a un grado escolar. Recuérdese que se refieren al último grado que el niño o niña aprobó en la escuela. Una primera mirada indica las diferencias existentes en todos los grados entre pobres y no pobres y por sexo. Queda claro el mayor retraso al inicio de la escuela de los pobres. Conforme avanzan los grados, resulta también evidente que las niñas van sacando ventaja sobre los niños en ambas condiciones de pobreza, aunque no hay que perder de vista que en los últimos grados escolares ya tan sólo alrededor de la tercera parte de ellas continúa estudiando.

Hemos revisado ya la situación escolar de niñas y niños en edad de recibir la educación básica, especialmente de aquellos niños que viven en contextos de alta marginación rural. Destacamos que una alta proporción de niños, sobre todo de hogares en condición de pobreza extrema, ingresa tardíamente a la escuela. También encontramos una fuerte proporción de niños que dejan de asistir a la escuela a partir de los 11 años. Ya que no era posible establecer el vínculo directo entre estos dos fenómenos, buscamos una aproximación analizando la edad promedio de los niños y niñas en cada grado escolar aprobado y el número de años promedio aprobado a cada edad. El análisis mostró que entre los niños de las localidades marginadas que asisten a la escuela el rezago con respecto a la edad normativa es grande, y entre los que no asisten, mayor, particularmente después de los 11 años, de tal suerte que en muchos de estos casos es tan amplia la distancia entre la edad y el último grado alcanzado que se podría suponer que estos niños no reingresarán a la escuela. En otras palabras, surge la idea de que en las localidades rurales marginadas existe una relación causal entre edad al ingreso, rezago escolar y deserción.

Al exponer las fuentes de información señalamos que Progresa opera en localidades marginadas que cuentan con acceso a una escuela en la localidad o a una cercana, aunque puede haber diferencias en las distancias y los costos de transporte. Más importante que la oferta parecen ser las condiciones del contexto de las familias que residen en ellas. El problema se puede plantear de la siguiente forma: en un contexto donde se dispone de servicios educativos y en el cual la calidad de la educación podría suponerse similar en todas las escue- 


\section{GRAFICA 1}

Proporción de niños que asisten a la escuela por grado escolar, edad, sexo y condición de pobreza, localidades rurales marginadas
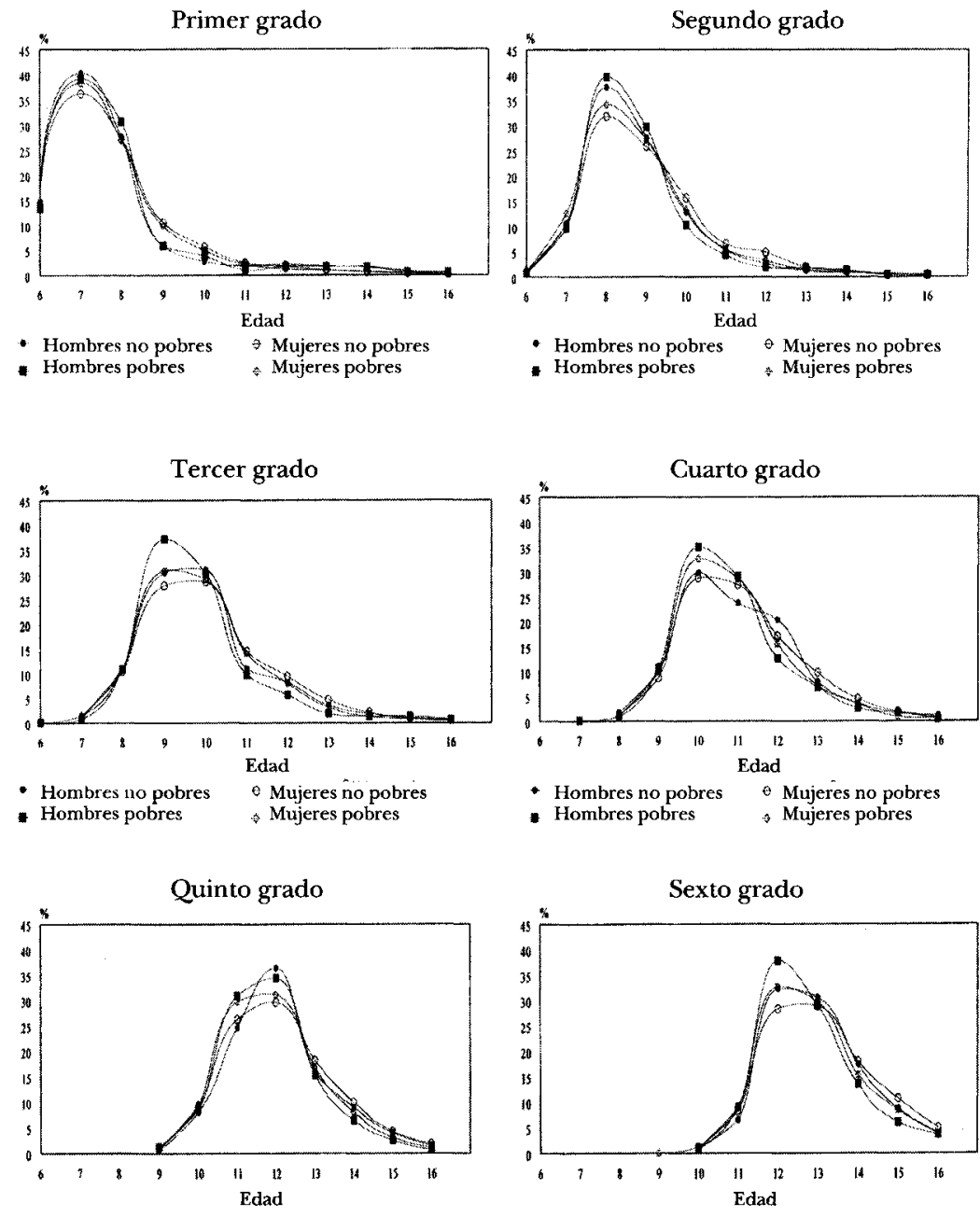

- Hombres no pobre

Mujeres no pobre

- Hombres pobres

* Mujeres pobres

- Hombres no pobres $\theta$ Mujeres no pobres

- Hombres pobres $*$ Mujeres pobres 
las ¿qué otros factores pueden ayudar a explicar la situación educativa de los niños? En la sección siguiente examinaremos la influencia de algunas características de los menores y de sus hogares en la asistencia a la escuela.

\section{Factores asociados con la asistencia escolar}

En México desde fines de los setenta y principios de los ochenta se ha desarrollado una línea de investigación sobre estrategias de vida, incorporación de los miembros de los hogares a los mercados de trabajo, participación laboral de las mujeres, migraciones, etc., que ha atribuido un lugar destacado a las características de los hogares, en particular la composición de parentesco, la jefatura, la relación consumidores-trabajadores, etc., y que ha mostrado su utilidad en los distintos campos en los que se ha aplicado. Muy recientemente se han hecho algunos esfuerzos para aplicarla a los estudios de la exclusión escolar a nivel nacional (Bracho, 1997). En el análisis que sigue incorporamos aspectos de esta perspectiva que han resultado de interés en estudios sobre jefatura de los hogares y trayectorias educativas de estudiantes universitarios (Hernández y Muñiz, 1996; Muñiz, 1997 y Muñiz y Hernández, 1999). También incorporamos variables relacionadas con las características de los niños.

\section{Características de la población en estudio}

Para iniciar diremos que de los 155691 niños de la muestra, $86.1 \%$ niños y niñas vive en hogares que se encuentran en condiciones de pobreza extrema. En relación con el sexo la distribución es prácticamente igual entre niños y niñas (51.3 y $48.7 \%$, respectivamente); asimismo los porcentajes por sexo en cada categoría de pobreza son similares.

Con respecto a la edad, se destaca una mayor proporción de niñas y niños de menores edades entre la población en condiciones de pobreza extrema: mientras entre los no pobres los niños de entre 6 y 10 años tienen proporciones de alrededor de 7\%, entre los pobres éstas ascienden a 10 por ciento. 
GUADRO 10

Condición de pobreza extrema por sexo en localidades marginadas rurales

\begin{tabular}{lccr}
\hline & Hombres & Mujeres & \multicolumn{1}{c}{ Total } \\
\hline No pobres & 11126 & 10546 & 21672 \\
& $(14.1)$ & $(86.2)$ & $(13.9)$ \\
Pobres & 67935 & 66081 & 134019 \\
& $(85.9)$ & $(86.2)$ & $(86.1)$ \\
Total & 79061 & 76627 & 155691 \\
& 100 & 100 & 100 \\
\hline
\end{tabular}

GUADRO 11

Distribución por edad, sexo y condición de pobreza en localidades marginadas rurales

\begin{tabular}{rrrrrrrr}
\hline & \multicolumn{3}{c}{ No pobres } & & \multicolumn{3}{c}{ Pobres } \\
\cline { 2 - 3 } \cline { 6 - 7 } \cline { 6 - 7 } & Hombres & Mujeres & Total & Hombres & Mujeres & Total \\
\hline 6 & 6.54 & 6.17 & 6.36 & & 9.98 & 10.26 & 10.12 \\
7 & 7.06 & 6.46 & 6.76 & & 9.82 & 10.17 & 9.99 \\
8 & 7.70 & 7.72 & 7.71 & & 10.06 & 10.01 & 10.04 \\
9 & 7.05 & 7.62 & 7.33 & & 9.17 & 9.35 & 9.26 \\
10 & 8.24 & 8.25 & 8.25 & & 10.19 & 9.83 & 10.01 \\
11 & 7.54 & 8.03 & 7.78 & & 8.99 & 8.88 & 8.93 \\
12 & 11.20 & 10.58 & 10.90 & & 9.41 & 9.42 & 9.42 \\
13 & 9.95 & 10.68 & 10.30 & & 8.55 & 8.64 & 8.60 \\
14 & 10.87 & 11.01 & 10.94 & & 8.50 & 8.33 & 8.42 \\
15 & 10.97 & 10.90 & 10.94 & & 8.24 & 7.91 & 8.08 \\
16 & 12.89 & 12.57 & 12.74 & & 7.09 & 7.19 & 7.14 \\
Total & 100.00 & 100.00 & 100.00 & & 100.00 & 100.00 & 100.00 \\
\hline
\end{tabular}

Ahora describiremos algunas de las características de los hogares donde viven los menores, y posteriormente complementaremos la información distinguiendo niñas y niños en condiciones de pobreza extrema. Los hogares de los niños y niñas pobres son nucleares en mayor proporción, tienen un tamaño de aproximadamente un miembro más y el número de trabajadores promedio es mayor que en los hogares de los niños y niñas no pobres, y prácticamente sin diferencias por sexo. Poco más de 9 de cada 10 cuentan con un 
jefe varón que es cerca de tres años más joven que los jefes no pobres. $^{7}$

Los jefes de los hogares presentan diferencias en sus niveles de escolaridad y ocupación según su condición de pobreza. Mientras entre los jefes no pobres alrededor de $17 \%$ no tiene ningún nivel de escolaridad y quienes cuentan con estudios de primaria, o de secundaria y más son 45 y $36 \%$ respectivamente, entre los jefes de hogares pobres los que no cuentan con escolaridad son $29 \%$, la mitad tiene hasta primaria y sólo $21 \%$ cuenta con algún grado de secundaria o más.

Con respecto a la ocupación de los jefes de los hogares se observan también diferencias por condición de pobreza. Entre los jefes de los hogares no pobres, los jornaleros son cerca de $29 \%$ y alrededor de $21 \%$ son obreros y trabajadores por su cuenta. Los jefes jornaleros entre los hogares pobres representan $45 \%$, los obreros $12 \%$ y los que trabajan por cuenta propia $18 \%$. Por último, la proporción de los hogares en condición de extrema pobreza que tienen niños entre 0 y 5 años es prácticamente el doble que en los hogares no pobres.

Ahora bien, con respecto a las características de los niños entre 6 y 16 años podemos observar que mientras entre los no pobres los hablantes de lengua indígena representan $14 \%$, entre los pobres extremos esta proporción asciende a poco más de una cuarta parte de los niños, sin diferencias por sexo. En un contexto de prácticamente una mayoría de niños que son solteros, cabe resaltar la pequeña proporción sobre todo de niñas que a estas edades se encuentran ya unidas o casadas ( $2.0 \%$ de las no pobres y $1.7 \%$ de las pobres).

La participación de los menores en los mercados de trabajo muestra diferencias por sexo, independientemente de la condición de pobreza; los niños tienen más del doble de participación laboral que las niñas. ${ }^{8} \mathrm{La}$ asistencia escolar presenta una situación similar a la descrita para el trabajo, siendo las niñas pobres las que tienen la más baja asistencia escolar y la más alta proporción de las que nunca han asistido. Al combinar la participación laboral y la asistencia vemos que alrededor de $5 \%$ de niños tanto pobres como no pobres realizan ambas actividades; el porcentaje de niñas en ambas actividades es me-

\footnotetext{
${ }^{7}$ Se trata de los atributos de los hogares de los niños analizados.

${ }^{8}$ Para conocer la participación laboral de los menores se preguntó sobre aquellos de ocho años y más, por lo que en este análisis se consideró que los de seis y siete años no trabajan.
} 
CUADRO 12

Características de los hogares y de los niños en localidades marginadas rurales por sexo y condición de pobreza

\begin{tabular}{|c|c|c|c|c|}
\hline & \multicolumn{2}{|c|}{ No pobres } & \multicolumn{2}{|c|}{ Pobres } \\
\hline & Hombres & Mujeres 1 & Hombres & Mujeres \\
\hline \multicolumn{5}{|l|}{ Composición de parentesco en el hogar } \\
\hline Nuclear & 70.2 & 69.7 & 74.6 & 73.7 \\
\hline Extenso & 28.8 & 29.3 & 24.9 & 25.7 \\
\hline Otro & 1.0 & 1.0 & 0.5 & 0.6 \\
\hline Tamaño promedio del hogar & 06.19 & 06.23 & 07.24 & 07.27 \\
\hline \multicolumn{5}{|l|}{ Sexo del jefe del hogar } \\
\hline Hombre & 90.6 & 90.4 & 92.3 & 92.1 \\
\hline Mujer & 9.4 & 9.6 & 7.7 & 7.9 \\
\hline Número promedio de trabajadores & 3.44 & 3.44 & 3.79 & 3.80 \\
\hline Edad promedio del jefe & 46.52 & 46.62 & 43.46 & 43.31 \\
\hline \multicolumn{5}{|l|}{ Escolaridad del jefe } \\
\hline Sin escolaridad & 17.8 & 17.4 & 29.2 & 28.7 \\
\hline Primaria & 45.5 & 45.8 & 49.7 & 49.7 \\
\hline Secundaria y más & 36.6 & 36.8 & 21.1 & 21.5 \\
\hline \multicolumn{5}{|l|}{ Ocupación jefe } \\
\hline No trabaja & 10.5 & 10.5 & 9.8 & 9.7 \\
\hline Jornalero & 29.2 & 28.7 & 45.1 & 44.6 \\
\hline Obrero & 20.6 & 20.6 & 12.2 & 12.9 \\
\hline Por cuenta propia & 22.0 & 22.4 & 18.1 & 17.8 \\
\hline Otro & 17.7 & 17.9 & 14.8 & 15.0 \\
\hline \multicolumn{5}{|l|}{ Niños de 0 a 5 años } \\
\hline No hay & 67.7 & 66.9 & 36.4 & 35.2 \\
\hline \multirow{2}{*}{\multicolumn{5}{|c|}{ Habla lengua indígena }} \\
\hline & & & & \\
\hline Si & 14.1 & 14.4 & 27.9 & 28.0 \\
\hline No & 85.9 & 85.6 & 72.1 & 72.0 \\
\hline \multicolumn{5}{|l|}{ Estado civil } \\
\hline Casado & 0.2 & 2.0 & 0.2 & 1.7 \\
\hline Soltero & 99.7 & 97.9 & 99.7 & 98.2 \\
\hline Otro & 0.1 & 0.1 & 0.1 & 0.2 \\
\hline \multicolumn{5}{|l|}{ Trabaja } \\
\hline Sí & 16.9 & 7.7 & 16.2 & 7.4 \\
\hline No & 83.1 & 92.3 & 83.8 & 92.6 \\
\hline \multicolumn{5}{|l|}{ Asistencia escolar } \\
\hline Sí & 80.6 & 77.2 & 77.0 & 73.7 \\
\hline No & 16.8 & 19.9 & 15.9 & 18.6 \\
\hline Nunca & 2.6 & 2.9 & 7.1 & 7.6 \\
\hline \multicolumn{5}{|l|}{ Asistencia escolar y trabajo } \\
\hline Trabaja-asiste & 5.0 & 2.1 & 5.3 & 2.5 \\
\hline Sólo trabaja & 11.9 & 5.5 & 10.9 & 4.9 \\
\hline Sólo asiste & 75.6 & 75.0 & 71.6 & 71.2 \\
\hline
\end{tabular}


CUADRO 12 (conclusión)

\begin{tabular}{lcccc}
\hline & \multicolumn{2}{c}{ No pobres } & \multicolumn{2}{c}{ Pobres } \\
\cline { 2 - 5 } & Hombres & Mujeres & Hombres & Mujeres \\
\hline No trabaja-no asiste & 7.5 & 17.3 & 12.2 & $\mathbf{2 1 . 4}$ \\
$\begin{array}{l}\text { Orden que ocupa el menor entre los niños } \\
\text { Mayor }\end{array}$ & 52.0 & 51.1 & 38.8 & $\mathbf{3 8 . 4}$ \\
Otro & 28.6 & 30.3 & 50.5 & $\mathbf{5 1 . 6}$ \\
Menor & 19.4 & $\mathbf{1 8 . 5}$ & 10.7 & $\mathbf{1 0 . 0}$ \\
\hline
\end{tabular}

nor que el de los niños. Las mayores diferencias por sexo las encontramos en la categoría que corresponde a aquellos que no trabajan y no asisten a la escuela, con porcentajes superiores entre las niñas: $17.3 \%$ de las no pobres y $21.4 \%$ de las pobres, mientras que los niños en esa situación son 7.5 y $12.2 \%$, respectivamente.

\section{Factores asociados a la asistencia escolar de los niños}

Hasta aquí hemos mostrado algunas de las características de los menores y sus hogares que consideramos son relevantes para entender su situación escolar. Ahora revisaremos cuáles son las variables que se asocian a la asistencia escolar. Consideramos que de los problenids examinados hasta ahora éste resulta el más relevante, dado que mientras los niños asistan a la escuela sus niveles de escolaridad continuarán incrementándose y el rezago pasará a un segundo término, lo mismo que la tardía incorporación al sistema escolar.

Para revisar estos factores utilizamos un modelo de regresión logística que permite analizar todos los elementos en forma conjunta y cuya variable dependiente es la asistencia escolar. ${ }^{9}$

En el cuadro 13 se presentan las razones de momios ajustadas estimadas, resultados de los modelos de regresión. Estas razones pue-

\footnotetext{
${ }^{9}$ La elección de modelos de este tipo responde a que la variable de interés es dicotómica y la regresión permite obtener un estimador de que ocurra o no el evento en cuestión: en este caso que un niño asista a la escuela. El estimador que se obtiene mediante la regresión logística permite calcular razones de momios, que es un indicador del riesgo relativo de un evento (Hosmer y Lemeshow, 1989).
} 
den interpretarse como una medida de "riesgo incrementado" de que ocurra el evento, en este caso el que los niños asistan a la escuela, cuando el niño tiene una característica específica, en comparación con los que no la tienen (que se definen como de "referencia"). Si el riesgo de que ocurra el evento no se incrementa o se reduce, la razón de momios es muy cercana a la unidad. Para este modelo se incorporan 13 variables, cinco de ellas relacionadas con las características de los hogares en los cuales viven los niños del análisis: condición de pobreza extrema, sexo, escolaridad, ocupación del jefe del hogar, y presencia de niños menores de cinco años. ${ }^{10}$ Se incluyeron dos tipos de variables que se refieren al niño; unas referentes a la relación del niño con los miembros del hogar, como la relación de parentesco que lo vincula con el jefe del hogar, y el orden y lugar que ocupa entre sus hermanos y los demás miembros menores de su hogar. Por otro lado, algunas de sus características más relevantes: sexo, edad, estado civil, lengua indígena, participación laboral, ingreso, y los años de escolaridad aprobados.

El cuadro 13 muestra los resultados de tres diferentes modelos, incluyendo el conjunto de variables utilizadas y las razones de momios ajustadas estimadas para aquellas que resultaron significativas $(p<0.05)$. Partiremos revisando la información correspondiente al modelo de los niños de 6 a 16 años que se presenta en la primera columna.

Inicialmente hay que hacer notar la presencia de tres factores asociados a los atributos de los hogares de los niños: aquellos niños que provienen de hogares no pobres, cuyos jefes cuentan con mayores niveles de escolaridad y un trabajo remunerado, tienen más probabilidades de asistir a la escuela en comparación con los que pertenecen a hogares cuya condición de pobreza es extrema y en los cuales el jefe tiene bajos niveles de escolaridad y una posición desventajosa en el mercado laboral.

De las dos variables que vinculan a los niños con los diferentes miembros de sus hogares encontramos que la presencia de menores de cinco años disminuye las probabilidades de que el niño asista a la escuela, y ser uno de los niños en edades intermedias dentro del gru-

\footnotetext{
${ }^{10}$ Para la ocupación del jefe del hogar se agruparon bajo el rubro de otras las siguientes categorías: patrón o empleador de un negocio, trabajador en negocio familiar sin retribución, trabajador sin retribución, miembro de una cooperativa, ejidatario o comunero.
} 
GUADRO 13

Factores asociados a la asistencia escolar de los niños entre 6 y 16 años de las localidades marginadas rurales, México, 1996-1998

\begin{tabular}{|c|c|c|c|}
\hline \multirow[b]{2}{*}{ Factores asociados } & \multicolumn{3}{|c|}{ Razón de momios } \\
\hline & 6 a 16 años & 6 a 10 años & 11 a 16 años \\
\hline \multicolumn{4}{|l|}{ Condición de pobreza } \\
\hline Pobre & 0.6123 & 0.6058 & 0.6444 \\
\hline No pobre & 1.00 & 1.00 & 1.00 \\
\hline \multicolumn{4}{|l|}{ Escolaridad del jefe del hogar } \\
\hline Sin escolaridad & 0.3752 & 0.4362 & 0.4095 \\
\hline Hasta primaria & 0.5502 & 0.6538 & 0.5768 \\
\hline Secundaria o más & 1.00 & 1.00 & 1.00 \\
\hline Años de escolaridad del niño & 0.7114 & 0.6501 & 0.9461 \\
\hline \multicolumn{4}{|l|}{ Orden que ocupa entre los niños } \\
\hline Mayor & - & - & - \\
\hline Mediano & 1.2442 & - & - \\
\hline Menor & 1.00 & 1.00 & 1.00 \\
\hline Ingreso total del niño & 0.9952 & - & 0.9963 \\
\hline \multicolumn{4}{|l|}{ Estado civil del niño } \\
\hline Soltero & 31.47 & - & 15.5758 \\
\hline Otro & 34.56 & - & 8.5347 \\
\hline Casado & 1.00 & 1.00 & 1.00 \\
\hline \multicolumn{4}{|l|}{ Hablante de lengua indigena } \\
\hline Sí & 1.1727 & - & 1.2546 \\
\hline No & 1.00 & 1.00 & 1.00 \\
\hline \multicolumn{4}{|l|}{ Sexo } \\
\hline Hombre & 1.6301 & - & 2.0948 \\
\hline Mujer & 1.00 & 1.00 & 1.00 \\
\hline Edad del niño & 0.8531 & 0.8731 & 0.6086 \\
\hline \multicolumn{4}{|l|}{ Participación laboral del niño } \\
\hline Sí & 0.1653 & 1.0735 & 0.1694 \\
\hline No & 1.00 & 1.00 & 1.00 \\
\hline \multicolumn{4}{|l|}{ Ocupación del jefe } \\
\hline No trabaja & 0.8561 & 0.8598 & 0.8294 \\
\hline Jornalero & 0.8397 & 0.8066 & 0.8320 \\
\hline Obrero & - & 0.8487 & - \\
\hline Cuenta propia & - & 0.8761 & - \\
\hline Otro & 1.00 & 1.00 & 1.00 \\
\hline \multicolumn{4}{|l|}{ Menores de 5 años en el hogar } \\
\hline No & 1.3017 & 1.1547 & 1.2402 \\
\hline Sí & 1.00 & 1.00 & 1.00 \\
\hline \multicolumn{4}{|l|}{ Parentesco con el jefe } \\
\hline Hijo & - & - & - \\
\hline Otro & 1.00 & 1.00 & 1.00 \\
\hline
\end{tabular}


po las incrementa ligeramente. El hecho de que el niño sea hijo del jefe o no, es independiente de su asistencia escolar.

La asistencia escolar se favorece cuando los niños tienen menor edad, son varones, hablantes de lengua indígena, solteros, y no tienen una participación laboral en el mercado de trabajo, en comparación con aquellos que tienen las situaciones contrarias cuando se han controlado todos los factores, es decir: conforme aumenta la edad de los niños van disminuyendo sus probabilidades de asistir a la escuela; los niños tienen mayores probabilidades que las niñas; los solteros multiplican sustantivamente sus probabilidades al igual que los que no trabajan.

Ahora bien, dada la importancia que registra la edad como determinante de la asistencia escolar y teniendo presente el atraso con el que los niños se incorporan al sistema escolar y la edad en que comienza a decrecer la asistencia, consideramos importante explorar los factores para dos diferentes grupos de niños: de 6 a 10 años y de 11 a 16 años. Los resultados se presentan en el cuadro 13 en las columnas 2 y 3 . Nótese que en el modelo correspondiente a los niños de 6 a 10 años se reduce el número de variables significativas. El pertenecer a una familia en condición de pobreza extrema reduce alrededor de $40 \%$ las probabilidades de que el niño asista a la escuela; algo similar sucede con el bajo nivel de escolaridad del jefe y con su posición en la ocupación. Los años de escolaridad acumulatos y la edad desempeñan también un papel relevante entre los factores asociados a la asistencia a la escuela. A mayor número de años te estudio se ve disminuida la probabilidad de que el niño asista a la sscuela cuando se ha controlado el resto de los factores. En este yrupo, la edad del niño presenta una probabilidad ligeramente mezor de abandono, sobre todo si se compara con el grupo de 11 a 16 เños.

Por otro lado, al revisar el modelo que corresponde a los niños de 11 $₫ 16$ años volvemos a encontrar prácticamente todas aquellas variables, a sxcepción del orden que ocupa entre los niños, que se presentaron en el nodelo general de la columna 1, con ligeras variaciones en los momios sero que apuntan en el mismo sentido. Esta situación nos indica que el rimer modelo presentado refleja con mayor claridad los factores famiiares y personales de la asistencia escolar de los niños de 11 a 16 años. lama la atención el menor peso que tiene en el modelo la condición de sobreza de sus hogares y el número de años de escolaridad acumulados, sí como el incremento en el riesgo que adquiere la edad del niño. 


\section{Comentarios finales}

En este trabajo hemos intentado hacer una revisión de la asistencia escolar de los niños entre 6 y 16 años, especialmente de aquellos que viven en localidades altamente marginadas. En el transcurso de esta revisión nos hemos acercado a problemas de ingresos tardíos, atrasos en la trayectoria normativa y abandonos tempranos. Del análisis ha quedado en claro que la proporción de niños que nunca asistieron a la escuela es diferencial por zonas de residencia con detrimento de los que viven en zonas rurales y dentro de éstas en localidades marginadas. Este análisis nos permitió identificar un problema de edad al ingreso a la escuela que define una situación de atraso ex-ante para un número de niños y sobre todo de niñas en condición de pobreza. Los datos sobre asistencia escolar también muestran irregularidades en la trayectoria que afectan a esos mismos grupos. Tomado en conjunto, lo anterior lleva a sugerir que existe una trayectoria escolar muy diferente de la normativa, y que ésta parece asociarse con variaciones en los cursos de vida de los niños pobres que afectan negativamente sus posibilidades de educarse. Esta situación nos lleva en consecuencia a tomar con mucha cautela la aceptación sin crítica del supuesto de trayectorias normativas con que suele operar la investigación. Al parecer influidos por la idea de que en lo fundamental se ha resuelto el problema del acceso, la mayoría de los estudios realizados en México ha considerado que las altas tasas de deserción que todavía subsisten son resultado de deficiencias de la escuela y de factores asociados con las características del medio escolar. La investigación ha mostrado que el rezago escolar es un factor de primera importancia para explicar la deserción.

Cabe insistir en que al adoptar estos enfoques se ha dejado de considerar el papel que juegan los contextos sociales y sociodemográficos en las trayectorias escolares de los niños. En este trabajo hemos tratado de recuperar esa visión desde una perspectiva que supone la vinculación entre los distintos aspectos de la problemática y muestra que problemas como el rezago escolar no se asocian necesariamente con las capacidades del niño ni con los efectos del medio escolar, sino con las condiciones de vida preexistentes de distintos sectores de la población. Entre los residentes de localidades rurales marginadas, ellas influyen sobre la edad en la que el niño ingresa al sistema escolar situándolo desde entonces en una situación de atraso. Además, dificultan la asistencia regular y presionan por una salida temprana. El 
curso de vida define el rango de edad en el que el niño debe de estudiar, más que los grados que debe aprobar. Por ello, mientras el niño está en ese rango de edad asiste a la escuela y sólo dificulta su asistencia un ingreso tardío o la necesidad de trabajar; en cambio, cuando ha excedido esa edad, la asistencia a la escuela se dificulta por factores tales como el número de grados que ha aprobado, el número de miembros en su hogar, su estado civil, su participación laboral y el monto de sus ingresos. Todo ello enmarcado en una clara distribución de roles y diferencias de género que ponen en notable desventaja a las niñas, sobre todo a las pobres.

\section{Bibliografía}

Bracho González, Teresa (1997), "La exclusión de la educación básica. Decisiones familiares sobre escolarización", documento de trabajo núm. 58 , México, División de Administración Pública, CIDE.

Guevara Niebla, Gilberto (comp.) (1992), La catástrofe silenciosa, México, FCE.

Hernández Franco, Daniel y Patricia E. Muñiz M. (1996), "¿Qué es un jefe de hogar?", Sociológica, vol. 11, núm. 32.

Hosmer, David y Stanley Lemeshow (1989), Applied Logistic Regression, Nueva York, John Wiley and sons.

Muñiz M., Patricia E. (1997), Trayectorias educativas y deserción universitaria en los ochenta, México, ANuies (Temas de Hoy en la Educación Superior, 19).

— y Daniel Hernández Franco (1999), "Los atributos de la jefatura del hogar", Estudios Demográficos y Urbanos, vol. 14, núm. 2 (41).

Muñoz Izquierdo, Carlos (1994), "El síndrome del atraso escolar y el abandono del sistema educativo", en Carlos Muñoz Izquierdo, La contribución de la educación al cambio social, México, Guernica, pp. 27-105.

- y Sonia Lavín de Arrivé (1988), "Estrategias para mejorar el acceso y la permanencia en educación primaria", en Carlos Muñoz Izquierdo (ed.), Calidad, equidad y eficiencia de la educación primaria: estado actual de las investigaciones realizadas en América Latina, México, Centro de Estudios Educativos, pp. 121-187.

Muñoz García, Humberto y María Herlinda Suárez Zozaya (1996), Perfil educativo de la población mexicana, México, INEGI/CRIM-UNAM/ISSUNAM. 